\title{
Natural Radioactive Environments as Sources of Local Disequilibrium for the Emergence of Life
}

\author{
Thiago Altair, ${ }^{1,2,{ }^{*}}$ Larissa M. Sartori, ${ }^{3}$ Fabio Rodrigues, ${ }^{4}$ Marcio G.B. de Avellar, ${ }^{5}$ and Douglas Galante ${ }^{1,2}$
}

\begin{abstract}
Certain subterranean environments of Earth have naturally accumulated long-lived radionuclides, such as ${ }^{238} \mathrm{U}$, ${ }^{232} \mathrm{Th}$, and ${ }^{40} \mathrm{~K}$, near the presence of liquid water. In these natural radioactive environments, water radiolysis can produce chemical species of biological importance, such as $\mathrm{H}_{2}$. Although the proposal of radioactive decay as an alternative source of energy for living systems has existed for $>30$ years, this hypothesis gained strength after the recent discovery of a peculiar ecosystem in a gold mine in South Africa, whose existence is dependent on chemical species produced by water radiolysis. In this study, we calculate the chemical disequilibrium generated locally by water radiolysis due to gamma radiation. We then analyze the possible contribution of this disequilibrium for the emergence of life, considering conditions of early Earth and having as reference the alkaline hydrothermal vent theory. Results from our kinetic model point out the similarities between the conditions caused by water radiolysis and those found on alkaline hydrothermal systems. Our model produces a steady increase of $\mathrm{pH}$ with time, which favors the formation of a natural electrochemical gradient and the precipitation of minerals with catalytic activity for protometabolism in this aqueous environment. We conclude by describing a possible free-energy conversion mechanism based on protometabolism, which could be a requisite for the emergence of life in Hadean Earth. Key Words: Origin of life-Natural radioactive environmentsRadiolysis-Protometabolism-Bioenergetics-Alkaline hydrothermal systems. Astrobiology 20, 1489-1497.
\end{abstract}

\section{Introduction}

I T IS WELL KNOWN that the subsurface of Earth hosts most of the prokaryotic biomass of the planet (Whitman et al., 1998; Labonté et al., 2015). At depths $>1 \mathrm{~km}$ below sea level, the environments have extreme conditions compared with superficial or oceanic environments, such as absence of oxygen, nutrients, sunlight, and sparse sources of energy (Omar et al., 2003; Colman et al., 2017). In some of these deep regions, there are natural deposits of radioactive minerals, such as at gold mines of the southern part of Africa (Lippmann et al., 2003; Omar et al., 2003; Chivian et al., 2008; Adam et al., 2018), or uranium deposits in Canada (Dubessy et al., 1988; Richard et al., 2012). Recently, it has been proposed that radioactive environments may be an interesting scenario for the emergence of life on early Earth, considering those on the surface (Adam, 2007) or deep underground (Ebisuzaki and Maruyama, 2017; Maruyama et al., 2019). This results from the chemical diversity pro- duced by water radiolysis (see Eq. 1) and capacity to produce chemical energy comparable with that of the Urey-Miller experiment (Cataldo and Iglesias-Groth, 2017; Ebisuzaki and Maruyama, 2017; Maruyama et al., 2019). Also, as our work details, preliminary analysis showed that some of these natural radioactive environments (NREs) have similar physicochemical conditions when compared with alkaline hydrothermal vent (AHV) systems, now considered one of the most promising environments for the emergence of life (Russell et al., 1989; Martin et al., 2008; Lane and Martin, 2012; Ebisuzaki and Maruyama, 2017; Branscomb and Russell, 2018a).

$$
\mathrm{H}_{2} \mathrm{O} \stackrel{\text { Ionizing radiation }}{\longrightarrow} \mathrm{e}_{\mathrm{aq}}^{-}, \mathrm{H} \cdot, \mathrm{HO} \cdot, \mathrm{HO} \cdot{ }_{2}, \mathrm{H}_{2} \mathrm{O}_{2}, \mathrm{H}^{+}, \mathrm{OH}^{-}, \mathrm{H}_{2}
$$

The importance of water radiolysis as a source of energy and of chemical species to sustain a living system has

\footnotetext{
${ }^{1}$ Brazilian Synchrotron Light Laboratory (LNLS), Brazilian Center for Research in Energy and Materials (CNPEM), Campinas, Brazil.

${ }^{2}$ Instituto de Física de São Carlos, Universidade de São Paulo, São Carlos, Brazil.

${ }^{3}$ Instituto de Matemática e Estatística, Universidade de São Paulo, São Paulo, Brazil.

${ }^{4}$ Departamento de Química Fundamental Instituto de Química, Universidade de São Paulo, São Paulo, Brazil.

${ }^{5}$ Instituto de Ciências Ambientais, Químicas e Farmacêuticas, Universidade Federal de São Paulo, Diadema, Brazil.

*Present address: Instituto de Química de São Carlos, Universidade de São Paulo, São Carlos, Brazil.
} 
already been postulated (Draganic and Draganic, 1971; Draganić et al., 1983; Draganic et al., 2005). However, it was only after the study of Chivian et al. (2008) that this hypothesis became factual. The authors described a lithoautotrophic microbial specie whose survival is dependent on redox reactions involving radiolysis-produced compounds. The Candidatus Desulforudis audaxviator bacterium was found to prevail in a deep subsurface region $\sim 2.8 \mathrm{~km}$ below the surface in fracture water at the Mponeng gold mine in the Witwatersrand Basin, South Africa, in a hot $\left(>60^{\circ} \mathrm{C}\right)$ and alkaline $(\mathrm{pH}=9.3)$ environment (Lin et al., 2006; Chivian et al., 2008; Zhou et al., 2011). Interestingly, the temperatures of the hydrothermal fluid formed in the vents of the lost city hydrothermal field system are in the range of $40-75^{\circ} \mathrm{C}$, and the $\mathrm{pH}$ is in the range of $9-11$. The difference between both environments is related to the energy source. The formation of hydrothermal fluid and the energy source in these systems both result from serpentinization reaction (Lowell, 2002; Russell and Arndt, 2004; Martin et al., 2008) (see details in Supplementary Material).

Despite the importance of energy sources and disequilibrium for life as we know it, the so-called AHV theory focuses on the specificity of this source and mainly on the mechanism of free energy conversion (or entropy conversion) that maintains a living system in its necessary far-from-equilibrium condition (Schrodinger, 1946; Murphy and O'Neill, 1995; Russell et al., 2013; Branscomb et al., 2017). Modern organisms use complex and specific protein-based nanoengines driven by chemiosmotic gradients linked to metabolic pathways (Boyer, 1997; Branscomb and Russell, 2013; Sousa et al., 2013; Sojo et al., 2016), a universal biological setting (Goodsell, 2009; Branscomb and Russell, 2018b). In these mechanisms, the chemiosmotic gradients are maintained by semipermeable membranes that restrict the diffusion of chemical species, while crossing through these membranes is mediated by specific and intricate converters that to the transduction of the chemical energy stored in the gradients (Branscomb and Russell, 2013; Russell et al., 2013). Finally, the AHV theory states that hydrothermal systems that were present on early Earth could provide an analogous and necessary setting for the emergence of the universal biological setting of living systems (Russell and Arndt, 2004; Martin et al., 2008; Lane et al., 2010; Branscomb and Russell, 2013, 2018a). Instead of modern complex enzymes as the first steps of life emergence in an early AHV scenario, minerals could work as catalysts that couple the generated chemiosmotic gradient to protometabolic pathways (Russell and Martin, 2004; Muñoz-Santiburcio and Marx, 2016; Muchowska et al., 2017; Varma et al., 2017). In this theory, the coupling would result in free-energy conversion, and those mineral catalysts could be constituted of iron and sulfur minerals ( $\mathrm{Fe}-\mathrm{S}$ minerals), or iron oxyhydroxides, also known as green rusts (Nitschke et al., 2013; Duval et al., 2019). Such a scenario would be driven by $\mathrm{pH}$ and redox gradients between the hydrothermal fluid and early ocean (Branscomb and Russell, 2013; Ang et al., 2015; Yamamoto et al., 2017; Barge et al., 2018; Ooka et al., 2019). Thus, this could be a requisite for the emergence of life on Hadean Earth.

Some studies on the AHV theory claim that Fe-S minerals (e.g., greigite [Fe3S4] or mackinawite [FeS]) would have clustered into the precipitates of the vents under the conditions of the early Earth. These propositions are based on early ocean composition and hydrothermal fluid conditions (Russell and Hall, 1997; Russell and Martin, 2004; Möller et al., 2017). Also, an important feature is that the clusters of the $\mathrm{Fe}-\mathrm{S}$ minerals are morphologically similar to active sites of essential enzyme cofactors in the acetyl-CoA synthesis pathway (Wächtershäuser, 1990; Huber and Wachterhauser, 1997; Russell and Hall, 1997; Russell and Martin, 2004; Sojo et al., 2016). This pathway unites carbon and energy metabolisms in Bacteria and Archaea domains, and it is expected to have been present in the last universal common ancestor (Lane et al., 2010; Sojo et al., 2016) (see Supplementary Material).

Thus, in this study, we have developed a numerical model to analyze the generation of chemical disequilibrium by water radiolysis due to gamma radiation from radioactive decay of ${ }^{238} \mathrm{U}$ - and ${ }^{232} \mathrm{Th}$-containing minerals, and ${ }^{40} \mathrm{~K}$ dissolved in early ocean waters. Furthermore, we estimated the influence of gamma ray radiolysis on conditions found in habitable NREs, such as those that host Ca. D. audaxviator. Considering that similar physicochemical conditions and the predominance of reducing species are found in NREs, analogous to alkaline vents systems, we have analyzed a mineral-based transduction model for these systems based on AHV models. In summary, the main objective of this work is to evaluate the possible contributions of NREs to the origins of life. This evaluation is based on analogous thermodynamic and kinetic arguments that also support the AHV theory. To this purpose, we calculated how water radiolysis contributes to the conditions already mentioned in NREs. Finally, considering that NREs have no dependence on a particular mineral interaction as an energy source (as occurs to AHVs), its existence is a direct consequence of the formation of rocky celestial bodies (Altair et al., 2018), and thus it is possible to extend this origins of life scenario to planetary bodies throughout the Solar System and beyond (Bouquet et al., 2017; Altair et al., 2018). Major targets in the search for life within the Solar System include the icy moons of the giant planets-such as Europa and Enceladus (Grasset et al., 2013).

\section{Methods}

The study did not required approval from the Institutional Review Board (IRB) as it did not involve any clinical trial nor the use of animals.

\subsection{Physicochemical conditions of the NREs and effects of water radiolysis in local chemical diversity}

The geochemical analysis of the radioactive environments at which Ca. D. audaxviator was discovered, in the region of Witwatersrand basin, is the starting point for the numerical models developed here. We considered long-lived radionuclides with concentrations comparable with those found in the region of the geological mineralized and nonmineralized strata in Witwatersrand. Also, we used the concentration for ${ }^{40} \mathrm{~K}$ that is estimated to have been present in the early oceans, in accordance with the work of Draganić et al. (1991), considering it as homogeneously dissolved. As a control, we performed the calculations using carbonate chondrite long-lived radionuclide concentrations, since they are primitive bodies of the Solar System. Hence, some studies have used carbonate chondrites as a model for early Earth (Javoy, 1995; Maruyama and 
Ebisuzaki, 2017). Numerical corrections were made for the decay rates of all radionuclides to reproduce the parameters as they would have been $4 \mathrm{Ga}$ ago. Table 1 gives the concentrations used in our model.

For the models developed here, we considered constant the escape yields $(\mathrm{G})$, and their values are found in the study of Pastina and Laverne (2001). Based on escape yields, we calculated the production rate of primary products as a function of time using Eqs. 2 and 3 (e.g., Spinks and Woods, 1964; Hoffmann, 1992; and Lin et al., 2005; Blair et al., 2007).

$$
\begin{gathered}
D_{\mathrm{eff}}=\frac{\rho \cdot \sum_{\mathrm{n}} D_{\mathrm{n}}}{\frac{1}{1-\varphi}+\frac{1}{S \cdot \varphi}} \\
Y_{\mathrm{P}}=\sum_{\mathrm{P}} D_{\mathrm{eff}} \cdot G_{\mathrm{p}}
\end{gathered}
$$

The indices $n$ and $p$ represent the referred radionuclide $\left({ }^{238} \mathrm{U},{ }^{232} \mathrm{Th}\right.$, or $\left.{ }^{40} \mathrm{~K}\right)$ and the radiolysis product, respectively; $Y_{\mathrm{P}}$ is the rate of formation of the radiolysis product $p$ in $\mathrm{mol} /(\mathrm{L} \cdot \mathrm{s}) ; \rho$ represents the density of the local rock matrix in $\mathrm{g} / \mathrm{cm}^{3} ; D_{\mathrm{n}}$ is the dose of gamma radiation emitted by the radionuclide $n$ in $\mathrm{MeV} /(\mathrm{kg} \cdot \mathrm{s})$, as calculated in Eq. 3; and $\varphi$ represents the rock porosity, which we considered to be equal to 0.1 . Note that this is the actual porosity observed in Witwatersrand (Lin et al., 2005) and the maximum value found in depths of $1000 \mathrm{~m}$ in Earth's crust (Vance et al., 2007). Finally, we represent by $S$ the stopping power of the rock matrix, as in the studies of Lin et al. (2005) and Blair et al. (2007), with a value $S=1.14$ for gamma radiation used here. Finally, the value of $G$ is in $\mathrm{mol} / \mathrm{MeV}$.

$$
D_{\mathrm{n}}=\frac{E \cdot \lambda \cdot \mathrm{c} \cdot N_{\mathrm{A}}}{A_{\mathrm{n}}}
$$

In Eq. 4, $E$ (MeV/decay) is the decay energy corrected for the loss of neutrinos through beta decay for $4 \mathrm{Ga}$ radionuclides; $\lambda=1 / T_{1 / 2}$ (decay per year) is the decay constant, $\mathrm{c}$ (ppm) is the radionuclide concentration, $N_{\mathrm{A}}$ is the Avogadro constant, and $A_{\mathrm{n}}(\mathrm{g} / \mathrm{mol})$ is the radionuclide molar mass.

To evaluate the effects of long-term radiolysis, we used the model based on the kinetic one presented in the study of Pastina and Laverne (2001), testing different sets of equations that resulted in stable numerical results. The resulting solution after long-term radiolysis of the early ocean, which had considerable chemical diversity, is referred to as "radiolytic fluid" throughout this article. The chemical reactions used in the model are given in Supplementary Table S1. We developed a system of ordinary differential equations (ODEs) based on the rate law for each chemical equation from that system of reactions. The chemical reactions show different orders of magnitude for chemical reaction rates. As a result, we ended with a stiff ODE system, which required the application of appropriate methods for integration to get convergent and stable numerical solutions. Because of this, we used a Rosenbrock method for calculations, which is a class of implicit single-step methods that allows considerable variation in the integration step size and has unlimited stability regions (Hairer and Wanner, 1996; Freitas et al., 2009; Sartori, 2014).

\subsection{Chemiosmotic gradients in the interface with early ocean and catalytic mineral setting}

We considered an isothermal diffusion model in a continuous interface for the spatial distribution of the concentrations of the chemical species on the radiolytic fluid-ocean interface (see Supplementary Material section for a detailed discussion). We also considered the second Fick's law for the potential calculations, which provides the time and space diffusion effects. The diffusivity, $D_{\mathrm{p}}$, is considered constant, given the high dilution of the species on the early ocean environment (Crank, 1975). Finally, we calculated the thermodynamic forces in gradients, such as electrochemical potentials and chemical potentials, to obtain the free energy at the interface.

The electromotive force $(\mathrm{EMF}, \phi)$, which is associated with local redox potential, is calculated as discussed in the Supplementary Material section. Besides, we calculated the local chemical potential $\mu_{\mathrm{P}}$ from the $\operatorname{EMF} \phi$. The time range for diffusional migration, however, was arbitrarily chosen for a time of $\sim 1$ week. Nevertheless, the difference in the time range would change only of the order of magnitude of the gradient region and would not change the values of the gradients' parameters.

Finally, we compared the thermodynamic parameters calculated for the gradients with the energetic demand for the initial step of the acetyl-CoA synthesis pathway, which is used here as a reference for the protometabolic step, which reduces $\mathrm{CO}_{2}$ to formaldehyde. Also, we used these parameters to evaluate the plausibility of the presence and stability of minerals such as calcium carbonate $\left(\mathrm{CaCO}_{3}\right)$, pyrite $\left(\mathrm{FeS}_{2}\right)$, mackinawite, and greigite. These minerals may be combined

\begin{tabular}{|c|c|c|c|c|c|c|}
\hline Radionuclide & $\begin{array}{c}\text { Natural } \\
\text { abundance } \\
(\text { atom \% })^{\mathrm{a}}\end{array}$ & $\begin{array}{l}\text { Concentration } \\
\text { in chondrite } \\
(p p b)^{\mathrm{b}}\end{array}$ & $\begin{array}{c}\text { Concentration } \\
\text { in mineralized } \\
\text { strata in } \\
\text { Witwatersrand }(\mathrm{ppm})^{\mathrm{c}}\end{array}$ & $\begin{array}{c}\text { Concentration } \\
\text { in nonmineralized } \\
\text { strata in } \\
\text { Witwatersrand }(\mathrm{ppm})^{\mathrm{c}}\end{array}$ & $\begin{array}{l}\text { Half-life } \\
\text { (years) }^{\mathrm{a}}\end{array}$ & $\begin{array}{c}\gamma \text { decay } \\
\text { energy } \\
(\text { MeV/decay })^{\mathrm{d}}\end{array}$ \\
\hline${ }^{40} \mathrm{~K}$ & $0.0117(1)$ & 105 & $380^{\mathrm{e}}$ & $380^{\mathrm{e}}$ & $1.25 \times 10^{9}$ & 0.1566 \\
\hline${ }^{232} \mathrm{Th}$ & 100 & 40 & 15 & 11 & $1.4 \times 10^{10}$ & 2.2447 \\
\hline${ }^{238} \mathrm{U}$ & $99.2742(10)$ & 12 & 271 & 3 & $4.46 \times 10^{9}$ & 1.7034 \\
\hline
\end{tabular}
to form carbonate structures with clusters of iron minerals.

Table 1. Radionuclides Used for the Modeling of Chemical Species' Production by Water Radiolysis

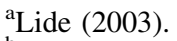

${ }^{\mathrm{b}}$ Waite et al. (2017).

${ }^{\mathrm{c}}$ Lefticariu et al. (2010).

${ }^{\mathrm{d}}$ Blair et al. (2007).

${ }^{\mathrm{e}}$ Concentration estimated for early Earth (Draganić et al., 1991).
} 
For this last-mentioned analysis, we considered the radiolytic fluid-early ocean interface with temperatures from $60^{\circ} \mathrm{C}$ to $5^{\circ} \mathrm{C}$ and pressure of $\sim 0.25 \mathrm{kbar}$, which are considered feasible for a naturally radioactive environment (Dubessy et al., 1988). We inferred the stability of $\mathrm{Fe}-\mathrm{S}$ minerals from their stability diagrams (the potential/pH diagram).

\section{Results}

\subsection{Kinetic model results for early ocean radiolysis}

Figure 1 shows the local chemical diversity of a radiolytic fluid in a naturally radioactive environment due to the longterm radiolysis of a mildly acidic $(\mathrm{pH}=5)$ early ocean.
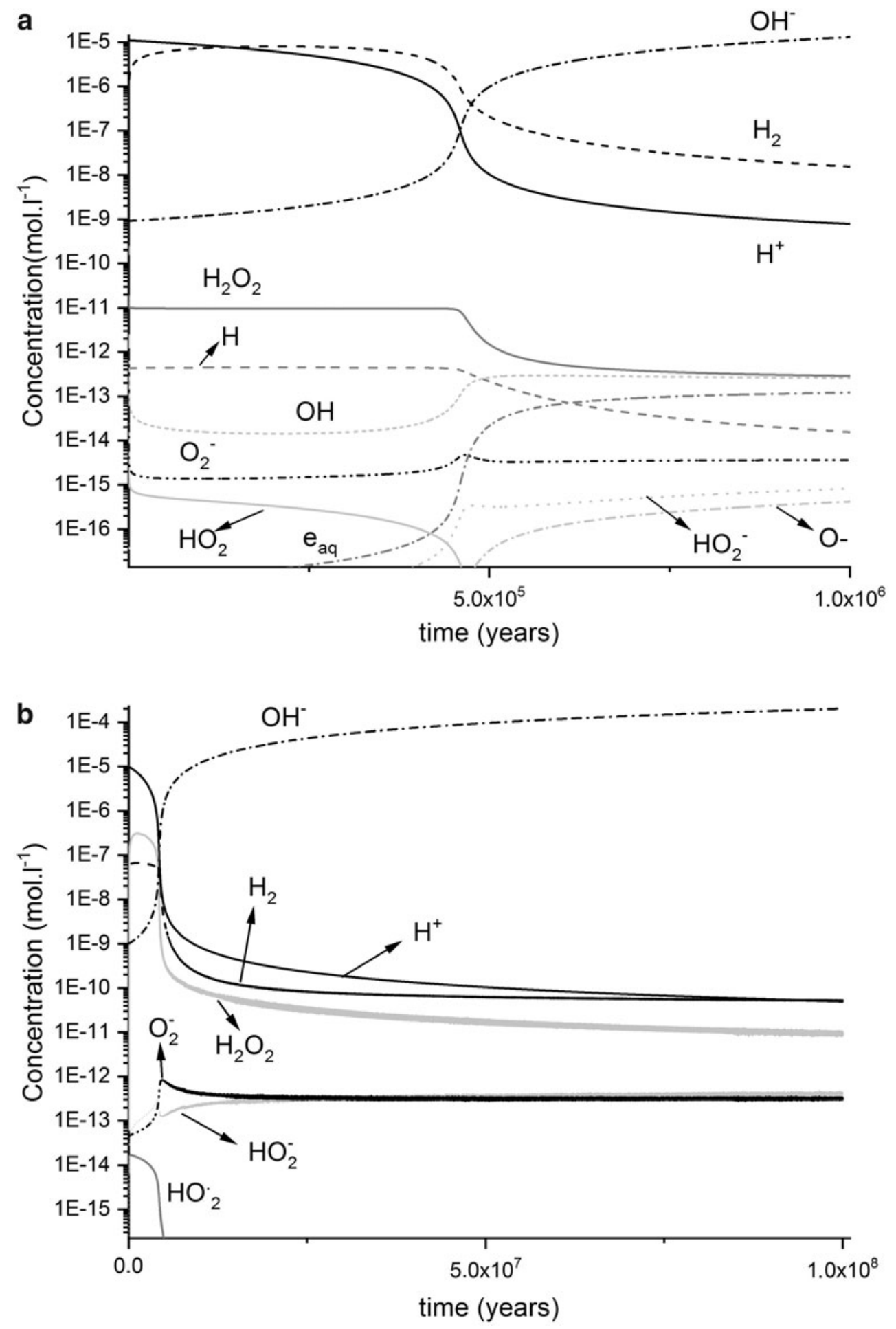

FIG. 1. Results for long-term water radiolysis of early ocean production of chemical species. The concentrations are presented as a function of time in years. There are two sets of results considering: (a) concentration of radionuclides similar to Witwatersrand and a mildly acidic primitive ocean $(\mathrm{pH}=5)$ and $(\mathbf{b})$ concentration of radionuclides similar to carbonaceous chondrite (Table 1), which is used as control and considering a mildly acidic early ocean $(\mathrm{pH}=5)$. 
FIG. 2. Distribution of physicochemical parameter results-EMF $(\phi)$ and chemical potential $(\mu)$-in time and space from a one-dimensional diffusion model associated with radiolytic fluidearly ocean interface, for $T=5^{\circ} \mathrm{C}$. In $x=0$, it was considered the chemical diversity resulting from the numerical model for long-term mildly acidic $(\mathrm{pH}=5)$ early ocean water radiolysis. $\mathrm{EMF}$, electromotive force.

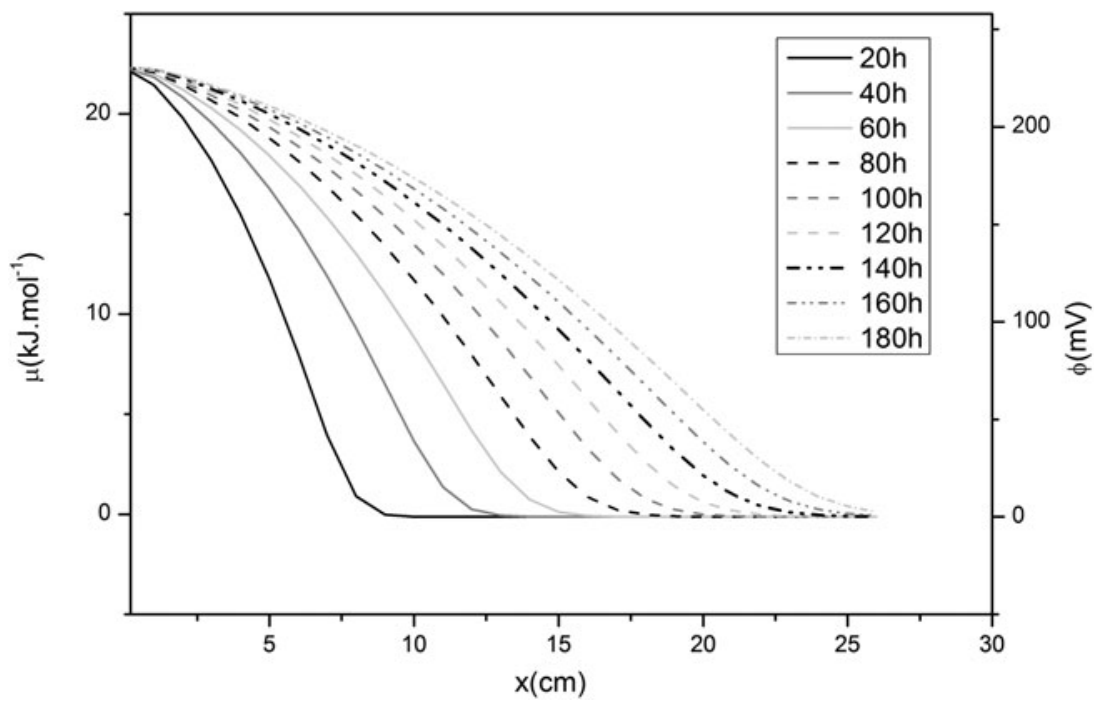

There is an initial growth of the concentration of products, which characterizes the moment at which the radiolysis phenomenon dominates and provides the primary products. This lasts until the chemical reactions start to prevail and exhibit a quasi-steady-state condition for the concentration of products. From Fig. 1, we see that the concentrations of $\mathrm{H}_{2}, \mathrm{H}^{+}$, and $\mathrm{OH}^{-}$ions are much higher than that of other radical species, that is, electrons $\left(\mathrm{e}^{-}\right.$aq $)$and hydrogen peroxide $\left(\mathrm{H}_{2} \mathrm{O}_{2}\right)$. This reflects the chemical instability of these last species concerning previous molecular ones. By comparing the difference in radionuclide concentration for the considered scenarios, the results show that this quantity affects the resulting chemical diversity. Figure 1a shows results when using radionuclide concentration from the Witwatersrand region (corrected, as mentioned in the "Methods" section, the activity of these to $4 \mathrm{Ga}$ ). In contrast, in Fig. 1b, which represents a model based on radionuclide concentrations of chondrites, the $\mathrm{H}_{2}$ reaches a concentration of up to three orders of magnitude lower than the case depicted in Fig. 1a (see also Supplementary Material for results in other scenarios).

\subsection{Chemiosmotic gradients formed in radiolytic fluid-early ocean interface}

In Figure 2, we present the EMF $(\phi)$ and chemical potential $(\mu)$ distribution in the radiolytic fluid-early ocean interface. These are the results of the diffusion of the prevalent products of radiolysis reported in the last section to a mildly acid early ocean model. The figure shows that local free energy is available from the chemical disequilibrium generated by water radiolysis to drive prebiotic transduction reactions. It is also apparent, from Fig. 2, a local reducing environment with an electrochemical potential up to 230 $\mathrm{mV}$ and chemical potential, up to $22 \mathrm{~kJ} / \mathrm{mol}$.

\subsection{Analysis of precipitation of mineral catalysts in the interface}

At first approach, it is reasonable to expect that carbonates would precipitate in the radiolytic fluid-ocean interface, as shown in Fig. 3, considering that its precipitation is related to early ocean composition in contact with the alkaline medium. And according to the stability diagram of these
FIG. 3. Stability regions of carbonate, iron, and sulfur minerals in the radiolytic fluid-early ocean interface. It presents the variation of $\mathrm{pH}$ and the $\log$ of the EMF as a function of the distance from the radioactive source after stabilization of the values (after 180 hours of free diffusion of the chemical species production).

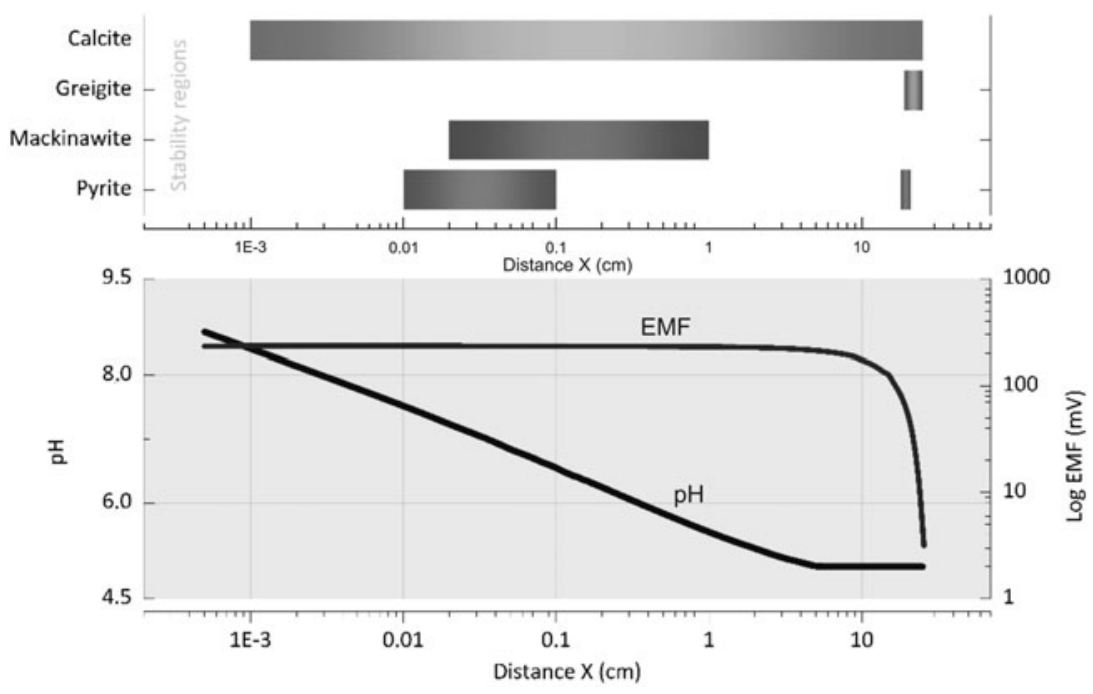


minerals (Garrels and Christ, 1965; Rickard and Luther, 2007), it is expected that, in the radioactive environment, the calcium carbonate minerals would be in the form of calcite and not aragonite, as occurs in typical AHVs (Kelley, 2005). This situation is due to the typical temperature and pressure conditions associated with modern radioactive environments (Dubessy et al., 1988; Savary and Pagel, 1997; Lin et al., 2005). Hence, calcite has already been reported near the region of deposition of radioactive minerals (Hallbauer, 1986; Robb and Meyer, 1995; Omar et al., 2003; Chivian et al., 2008). Results shown in Fig. 3 report the feasibility of catalytic iron minerals in the region of an NRE, something that has already been reported or estimated (Ebisuzaki and Maruyama, 2017).

We observe from the $\phi / \mathrm{pH}$ diagram (Fig. 3) that, even in the presence of a low amount of sulfur and iron, some catalytic minerals are stable due to the strongly reducing conditions. The pyrite stability region is in a limited region, together with greigite and mackinawite close to the radioactive environment $(<1 \mathrm{~cm})$. Thus, Fig. 3 illustrates numerically the possibility of the formation of a mineral setting in NREs similar to those proposed in early AHV systems.

\section{Discussion}

The results of our kinetic model for long-term radiolysis compared with other models and geochemical measurements show its adequacy to elucidate the physicochemical conditions of a habitable NRE. As an example, the geo- chemical analysis of habitable NREs supports the resulted $\mathrm{H}_{2}$-rich and reducing radiolytic fluid. The final $\mathrm{pH}$ reached after hundreds of thousands of years of radiolysis shows an alkaline medium, similar to the NRE at which $C a$. $D$. audaxviator was described (Chivian et al., 2008). Although several models were tested for long-term radiolysis (Supplementary Figs. S4-S6), they were the models that considered $\mathrm{pH}=5$ that resulted in the mentioned conditions. Thus, these results may be important to stand in favor of the proposal for a mildly acid early ocean.

Interestingly, the results also show a $\mathrm{pH}$ shift occurring due to long-term water radiolysis, which interchanges $\mathrm{OH}^{-}$ and $\mathrm{H}^{+}$concentrations (Fig. 1). The inflection points on the $\mathrm{H}^{+}$and $\mathrm{OH}^{-}$curves that occur after $4.60 \times 10^{5}$ and $4.26 \times 10^{6}$ years considering the radionuclide concentration from Witwatersrand and chondrites, respectively. This shows the time when a naturally radioactive environment, as modeled, reaches an alkaline condition. The figure also indicates that, in environments with higher concentrations of radionuclides, the shift occurs at earlier times, which leads to different evolution paths for the geological settings. In contrast, in some models that consider an initially alkaline water medium, this $\mathrm{pH}$ shift occurs inversely, which means a lower final $\mathrm{H}^{+}$concentration (Supplementary Fig. S4-S6).

Radiolysis produced chemicals with higher concentrations than others in a radiolytic fluid, as shown in Fig. 1. In other words, after reaching a quasi-steady-state condition of the concentration, some products prevail in the radiolytic fluid. Mainly, $\mathrm{OH}^{-}$and $\mathrm{H}_{2}$ have significantly influenced the

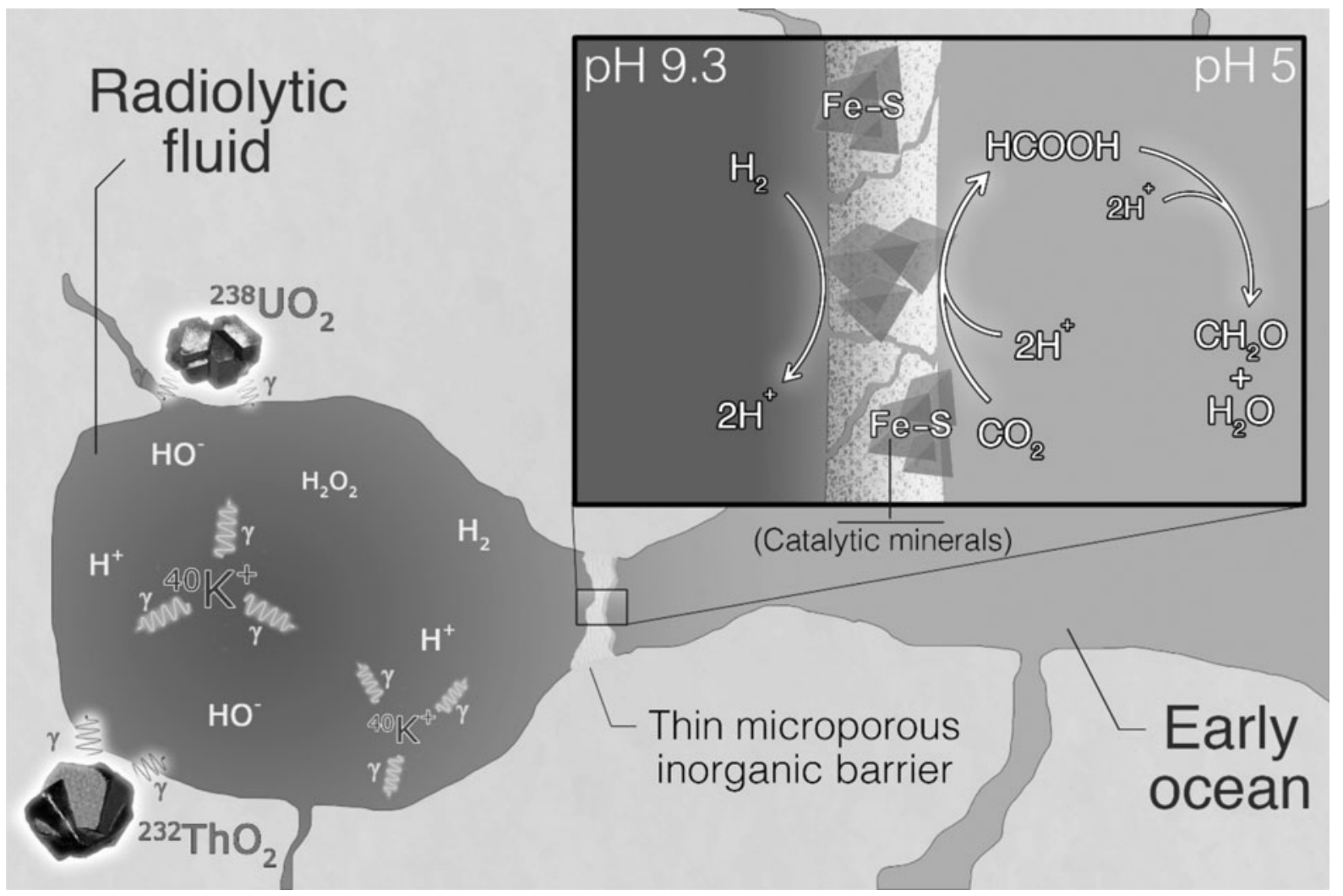

FIG. 4. Possible scenario for energy transduction on the interface between natural radioactive environment and Hadean ocean, based on the hypothesis for energy transduction in early alkaline hydrothermal system. It is considered Fe-S catalytic minerals that are stable on the interface (see section "Analysis of precipitation of mineral catalysts in the interface"). 
overall results for calculating the chemiosmotic gradients. The redox gradient, for example, associated with EMF $(\phi)$ showed a maximum of $230 \mathrm{mV}$, as presented in Fig. 2. This is comparable to the one generated by the gradients in AHVs or on mitochondria of modern cells $(\sim 200 \mathrm{mV})$ (Barge et al., 2012; Sojo et al., 2016). Also, it is enough for driving the first step of the acetyl-CoA synthesis pathway. This is estimated to occur at $94 \mathrm{mV}$, considering the $\mathrm{pH}$ gradient for the calculation (Supplementary Fig. S2).

The results shown in section "Analysis of precipitation of mineral catalysts in the interface" point out the feasibility of the precipitation of porous mineral interfaces that would contribute to the formation and maintenance of gradients and contain catalytic $\mathrm{Fe}-\mathrm{S}$ mineral clusters. The results support a hypothesis of an early protobiological transduction based on the acetyl-CoA synthesis pathway in NREs. Considering the analysis illustrated in Fig. 3, we proposed an analogous model for a possible primordial free energy conversion setting in a naturally radioactive environment on early Earth. Figure 4 basically shows this analogous model for the emergence of life based on the AHV theory (see "Introduction" section).

As shown in Fig. 4, a chemiosmotic gradient is formed because of the chemical potential difference at the interface (Fig. 2). The frustration of diffusion of species in the radiolytic fluid also occurs due to the formation of an inorganic barrier (possibly formed by calcite). It is possible, therefore, that this natural electrochemical gradient may be the driving force of protometabolisms, and in Fig. 4, we illustrate the first step of acetyl-CoA synthesis as an example. To be a catalyst of this reaction, the process of $\mathrm{Fe}-\mathrm{S}$ mineral incorporation is suggested since these minerals are stable in the formed gradient, as shown in Fig. 3.

As noted, in this study, sizes and absolute quantities are not calculated mainly due to our lack of information about the possible sizes of NREs on early Earth. A comparison using modern parameters, as performed by Atri (2016), can be achieved in this context as soon as more information is discovered about these early deep environments.

\section{Conclusions}

The theoretical study presented here indicates that natural radiolytic environments can produce physicochemical conditions that favor the origin and maintenance of life, even in regions devoid of sunlight, such as the icy moons of the Solar System, and thus extends our understanding of habitability in the Universe.

In analogy with modern AHVs, the radiolysis of water molecules produced by the decay of radionuclides such as ${ }^{238} \mathrm{U},{ }^{232} \mathrm{Th}$, and ${ }^{40} \mathrm{~K}$ at concentrations and activities consistent with the levels expected for the Hadean Earth can induce the formation of natural electrochemical gradients up to $230 \mathrm{mV}$. Radiolysis also facilitates the precipitation of porous minerals, such as calcite and iron sulfur minerals such as greigite, pyrite, and mackinawite, which show catalytic properties. Finally, radiolysis can create a situation of chemical disequilibrium with free energy enough to drive an initial step of a protometabolism. All of this after a quasistationary condition that was established after an unanticipated $\mathrm{pH}$-shifting phenomenon that occurred after a time of $\sim 1$ million years of radiolysis.
We propose NREs as unprecedented sites for the precipitation of catalytic minerals, synthesis of prebiotic molecules, and formation of chemical gradients necessary for the emergence of life. Together with hydrothermal systems, they represent potential sites for the emergence of metabolism not only on Earth but also on other bodies of the Solar System, such as the icy moons of the giant planets, in the absence of sunlight or geothermal sources.

\section{Funding Informations}

The authors thank FAPESP (projects 2016/06114-6 and 2016/08854-7), CAPES, and CNPq (project 424367/2016-5) for the financial support and the Research Unit in Astrobiology (NAP/Astrobio-PRP/USP) for the institutional support. The authors also thank Serrapilheira, Project number G-1709-20205.

\section{Author Disclosure Statement}

No competing financial interests exist.

\section{Funding Information}

\section{Supplementary Material}

Supplementary Material

Supplementary Figure S1

Supplementary Figure S2

Supplementary Figure S3

Supplementary Figure S4

Supplementary Figure S5

Supplementary Figure S6

Supplementary Table S1

\section{References}

Adam Z. (2007) Actinides and life's origins. Astrobiology 7: $852-872$.

Adam ZR, Hongo Y, Cleaves HJ, et al. (2018) Estimating the capacity for production of formamide by radioactive minerals on the prebiotic earth. Sci Rep 8:265.

Altair T, de Avellar MGBB, Rodrigues F, et al. (2018) Microbial habitability of europa sustained by radioactive sources. Sci Rep 8:260.

Ang R, Khan AU, Tsujii N, et al. (2015) Thermoelectricity generation and electron-magnon scattering in a natural chalcopyrite mineral from a deep-sea hydrothermal vent. Angew Chem Int Ed 54:12909-12913.

Atri D. (2016) On the possibility of galactic cosmic ray-induced radiolysis-powered life in subsurface environments in the universe. J R Soc Interface 13:20160459.

Barge LM, Doloboff IJ, White LM, et al. (2012) Characterization of iron-phosphate-silicate chemical garden structures. Langmuir 28:3714-3721.

Barge LM, Krause FC, Jones J-P, et al. (2018) Geo-electrodes and fuel cells for simulating hydrothermal vent environments. Astrobiology 18:1147-1158.

Blair CC, D'Hondt S, Spivack AJ, et al. (2007) Radiolytic hydrogen and microbial respiration in subsurface sediments. Astrobiology 7:951-970.

Bouquet A, Glein CR, Wyrick D, et al. (2017) Alternative energy: production of $\mathrm{H}_{2}$ by radiolysis of water in the rocky cores of icy bodies. Astrophys $J$ 840:L8. 
Boyer PD. (1997) The ATP synthase-a splendid molecular machine. Апnи Rev Biochem 66:717-749.

Branscomb E and Russell MJ. (2013) Turnstiles and bifurcators: the disequilibrium converting engines that put metabolism on the road. Biochim Biophys Acta Bioenerg 1827:62-78.

Branscomb E and Russell MJ. (2018a) Frankenstein or a submarine alkaline vent: who is responsible for abiogenesis? Part 1: what is life-that it might create itself? Bioessays 40:1-8.

Branscomb E and Russell MJ. (2018b) Frankenstein or a submarine alkaline vent: who is responsible for abiogenesis? Bioessays 40:1700182.

Branscomb E, Biancalani T, Goldenfeld N, et al. (2017) Escapement mechanisms and the conversion of disequilibria; the engines of creation. Phys Rep 677:1-60.

Cataldo F and Iglesias-Groth S. (2017) Radiation chemical aspects of the origins of life. J Radioanal Nucl Chem 311: 1081-1097.

Chivian D, Brodie EL, Alm EJ, et al. (2008) Environmental genomics reveals a single-species ecosystem deep within earth. Science 322:275-278.

Colman DR, Poudel S, Stamps BW, et al. (2017) The deep, hot biosphere: twenty-five years of retrospection. Proc Natl Acad Sci U S A 114:6895-6903.

Crank J. (1975) The Mathematics of Diffusion, $2^{\text {nd }}$ ed., Clarendon, Oxford, United Kingdom, p 414.

Draganic IG and Draganic ZD (1971) The Radiation Chemistry of Water. Academic Press, Inc., New York.

Draganić IG, Draganić ZD, and Altiparmakov D (1983) Natural nuclear reactors and ionizing radiation in the precambrian. Precambrian Res 20:283-298.

Draganić IG, Bjergbakke E, Draganić ZD, and Sehested K (1991) Decomposition of ocean waters by potassium-40 radiation $3800 \mathrm{Ma}$ ago as a source of oxygen and oxidizing species. Precambrian Res 52:337-345.

Draganic IG, Draganić IG, Draganic IG, et al. (2005) Radiolysis of water: a look at its origin and occurrence in the nature. Radiat Phys Chem 72:181-186.

Dubessy J, Pagel M, Beny J, et al. (1988) Radiolysis evidenced by $\mathrm{H}_{2} \mathrm{O}_{2}$ and $\mathrm{H}_{2}$-bearing fluid inclusions in three uranium deposits. Geochim Cosmochim Acta 52:1155-1167.

Duval S, Baymann F, Schoepp-cothenet B, et al. (2019) Fougerite: the not so simple progenitor of the first cells. Interface Focus 9:16-20.

Ebisuzaki T and Maruyama S. (2017) Nuclear Geyser model of the origin of life: driving force to promote the synthesis of building blocks of life. Geosci Front 8:275-298.

Freitas SR, Longo KM, and Rodrigues LF. (2009) Numerical modeling of the chemical composition of the atmosphere and its impacts on time, climate and air quality (translated from portuguese). Rev Brasil Meteorol 24:188-207.

Garrels RM and Christ C. (1965) Solutions, Minerals, and Equilibria. Harper \& Row, New York.

Goodsell DS. (2009) The Machinery of Life. Springer New York, New York.

Grasset O, Dougherty MKK, Coustenis A, et al. (2013) JUpiter ICy moons explorer (JUICE): an ESA mission to orbit ganymede and to characterise the jupiter system. Planet Space Sci 78:1-21.

Hairer E and Wanner G. (1996) Solving Ordinary Differential Equations II. Springer Series in Computational Mathematics, Springer Berlin Heidelberg, Berlin, Heidelberg, Germany.

Hallbauer DK. (1986) The Mineralogy and Geochemistry of Witwatersrand Pyrite, Gold and Uranium, and carbonaceous matter. In Mineral Deposits of Southern Africa, edited by
Anhaeusser CR and Maske S, Geological Society of South Africa, Johannesbourg, South Africa, pp 731-752.

Hoffmann BA. (1992) Isolated reduction phenomenon in red beds: a result of porewater radiolysis. In Water-Rock Interaction, edited by YK Kharaka and AS Maest, Springer Berlin Heidelberg, Berlin, Heidelberg, Germany, pp 503506.

Huber C and Wachterhauser G. (1997) Activated acetic acid by carbon fixation on $(\mathrm{Fe}, \mathrm{Ni}) \mathrm{S}$ under primordial conditions. Science 276:245-248.

Javoy M. (1995) The integral enstatite chondrite model of the earth. Geophys Res Lett 22:2219-2222.

Kelley DS. (2005) A serpentinite-hosted ecosystem: the lost city hydrothermal field. Science 307:1428-1434.

Labonté JM, Field EK, Lau M, et al. (2015) Single cell genomics indicates horizontal gene transfer and viral infections in a deep subsurface Firmicutes population. Front Microbiol 6: $1-11$.

Lane N, Allen JF, and Martin W (2010) How did LUCA make a living? Chemiosmosis in the origin of life. Bioessays 32: 271-280.

Lane N and Martin WF (2012) The origin of membrane bioenergetics. Cell 151:1406-1416.

Lefticariu L, Pratt LA, LaVerne JA, et al. (2010) Anoxic pyrite oxidation by water radiolysis products - a potential source of biosustaining energy. Earth Planet Sci Lett 292:57-67.

Lide DR (2003) CRC Handbook of Chemistry and Physics. CRC Press, Boca Raton, FL.

Lin L-H, Hall J, Lippmann-Pipke J, et al. (2005) Radiolytic $\mathrm{H}_{2}$ in continental crust: nuclear power for deep subsurface microbial communities. Geochem Geophys Geosyst 6, doi: 10.1029/2004GC000907.

Lin L-H, Wang P-L, Rumble D, et al. (2006) Long-term sustainability of a high-energy, low-diversity crustal biome. Science 314:479-482.

Lippmann J, Stute M, Torgersen T, et al. (2003) Dating ultradeep mine waters with noble gases and $36 \mathrm{Cl}$, Witwatersrand Basin, South Africa. Geochim Cosmochim Acta 67:45974619.

Lowell RP (2002) Seafloor hydrothermal systems driven by the serpentinization of peridotite. Geophys Res Lett 29:1531.

Martin W, Baross J, Kelley D, et al. (2008) Hydrothermal vents and the origin of life. Nat Rev Microbiol 6:805-814.

Maruyama S and Ebisuzaki T (2017) Origin of the earth: a proposal of new model called ABEL. Geosci Front 8:253274.

Maruyama S, Kurokawa K, Ebisuzaki T, et al. (2019) Nine requirements for the origin of Earth's life: not at the hydrothermal vent, but in a nuclear geyser system. Geosci Front 10:1337-1357.

Möller FM, Kriegel F, Kieß M, et al. (2017) Steep pH gradients and directed colloid transport in a microfluidic alkaline hydrothermal pore. Angew Chem Int Ed 56:2340-2344.

Muchowska KB, Varma SJ, Chevallot-Beroux E, et al. (2017) Metals promote sequences of the reverse Krebs cycle. Nat Ecol Evol 1:1716-1721.

Muñoz-Santiburcio D and Marx D. (2016) On the complex structural diffusion of proton holes in nanoconfined alkaline solutions within slit pores. Nat Commun 7:12625.

Murphy MP and O'Neill LAJ (1995) Order from disorder: the thermodynamics of complexity in biology. In What Is Life? The Next Fifty Years, edited by MP Murphy and LAJ ONeill, Cambridge University Press, Cambridge, United Kingdom, pp 161-174. 
Nitschke W, McGlynn SE, Milner-White EJ, et al. (2013) On the antiquity of metalloenzymes and their substrates in bioenergetics. Biochim Biophys Acta Bioenerg 1827:871-881.

Omar GI, Onstott TC, and Hoek J (2003) The Origin of deep subsurface microbial communities in the Witwatersrand Basin, South Africa as deduced from apatite fission track analyses. Geofluids 3:69-80.

Ooka H, McGlynn SE, and Nakamura R (2019) Electrochemistry at deep-sea hydrothermal vents: utilization of the thermodynamic driving force toward the autotrophic origin of life. ChemElectroChem 6:1316-1323.

Pastina B and Laverne JA (2001) Effect of molecular hydrogen on hydrogen peroxide in water radiolysis. $J$ Phys Chem A 105:9316-9322.

Richard A, Rozsypal C, Mercadier J, et al. (2012) Giant uranium deposits formed from exceptionally uranium-rich acidic brines. Nat Geosci 5:142-146.

Rickard D and Luther GW (2007) Chemistry of iron sulfides. Chem Rev 107:514-562.

Robb LJ and Meyer FM (1995) The Witwatersrand Basin, South Africa: geological framework and mineralization processes. Ore Geol Rev 10:67-94.

Russell MJ and Arndt NT (2004) Geodynamic and metabolic cycles in the Hadean. Biogeosci Discuss 1:591-624.

Russell MJ and Hall AJ (1997) The emergence of life from iron monosulphide bubbles at a submarine hydrothermal redox and pH front. J Geol Soc 154:377-402.

Russell MJ and Martin W (2004) The rocky roots of the acetylCoA pathway. Trends Biochem Sci 29:358-363.

Russell MJ, Hall AJ, and Turner D (1989) In vitro growth of iron sulphide chimneys: possible culture chambers for originof-life experiments. Terra Nova 1:238-241.

Russell MJ, Nitschke W, and Branscomb E (2013) The inevitable journey to being. Philos Trans R Soc B Biol Sci 368: 20120254.

Sartori LM (2014) Métodos Para Resolução de EDOs Stiff Resultantes de Modelos Químicos Atmosféricos. Universidade de São Paulo, São Paulo, Brazil.

Savary V and Pagel M (1997) The effects of water radiolysis on local redox conditions in the Oklo, Gabon, natural fission reactors 10 and 16. Geochim Cosmochim Acta 61:4479-4494.

Schrodinger E (1946) What Is Life? Cambridge University Press, Cambridge, United Kingdom.

Sojo V, Herschy B, Whicher A, et al. (2016) The origin of life in alkaline hydrothermal vents. Astrobiology 16:181197.
Sousa FL, Thiergart T, Landan G, et al. (2013) Early bioenergetic evolution. Philos Trans R Soc B Biol Sci 368:20130088.

Spinks JWT and Woods RJ (1964) An Introduction to Radiation Chemistry, $1^{\text {st }}$ ed., Wiley, New York.

Vance S, Harnmeijer J, Kimura J, et al. (2007) Hydrothermal systems in small ocean planets. Astrobiology 7:987-1005.

Varma SJ, Muchowska KB, Chatelain P, et al. (2017) Metals enable a non-enzymatic acetyl CoA pathway. bioRxiv 235523.

Wächtershäuser G (1990) Evolution of the first metabolic cycles (chemoautotrophy/reductive citric acid cycle/origin of life/ pyrite). Proc Natl Acad Sci U S A 87:200-204.

Waite JH, Glein CR, Perryman RS, et al. (2017) Cassini finds molecular hydrogen in the Enceladus plume: evidence for hydrothermal processes. Science 356:155-159.

Whitman WB, Coleman DC, and Wiebe WJ (1998) Prokaryotes: the unseen majority. Proc Natl Acad Sci U S A 95: 6578-6583.

Yamamoto M, Nakamura R, Kasaya T, et al. (2017) Spontaneous and widespread electricity generation in natural deepsea hydrothermal fields. Angew Chem Int Ed 56:5725-5728.

Zhou J, He Q, Hemme CL, et al. (2011) How sulphate-reducing microorganisms cope with stress: lessons from systems biology. Nat Rev Microbiol 9:452-466.

Address correspondence to: Thiago Altair

Brazilian Synchrotron Light Laboratory (LNLS) Brazilian Center for Research in Energy and Materials (CNPEM)

Av. Giuseppe Máximo Scolfaro, 10000 Campinas, SP 13083-100

Brazil

E-mail: thiago.altair.ferreira@usp.br

Submitted 29 May 2020

Accepted 30 July 2020

\section{Abbreviations Used}

$\mathrm{AHV}=$ alkaline hydrothermal vent $\mathrm{EMF}=$ electromotive force

$\mathrm{NRE}=$ natural radioactive environment

$\mathrm{ODE}=$ ordinary differential equation 